Dr Gary S. Robertshaw

is a marketing manager and fellow of the Institute of Direct Marketing.

Dr Norman E. Marr

is professor of marketing at the Huddersfield University

Business School.
Keywords: individual-level consumer data, targeting
Gary Robertshaw

15 Heron Close

Mountain

Queensbury

Bradford

West Yorkshire BD13 1NR, UK

Tel: +44 (0)1274 266007;

E-mail:

gary.robertshaw@cox.co.uk

\section{Consumer attitudes towards disclosing personal data for direct marketing}

\author{
Gary Robertshaw and Norman Marr \\ Received (in revised form): 18 October 2005
}

\begin{abstract}
The self-disclosure of individual-level consumer data, such as interests, opinions, beliefs, competitor spending habits and future purchase intentions, for direct marketing purposes is voluntary in nature. This raises the prospect that such information may be to some extent incomplete and unreliable. But the completeness and reliability of voluntarily disclosed personal data for direct marketing purposes have received little attention in the literature.

Using 157 personal interviews, this study quantifies typical levels of personal information omission and falsification in voluntary disclosures. The types of personal data that consumers tend to omit and falsify are identified, and an understanding of the underlying reasons is provided with a consideration of the implications for direct marketing practice.
\end{abstract}

\section{Background}

Market fragmentation and greater consumer eclecticism have accelerated the rejection of mass-marketing methods in favour of personalised marketing programmes that better meet the needs of the individual. ${ }^{1-3}$ This shift towards personalised forms of marketing has been accentuated by the introduction of digital communication channels, including the internet, interactive television and mobile telephones, allowing the direct marketing industry increasingly to communicate and interact with individual consumers on a real-time basis. ${ }^{4}$

Single decisions to target one market segment are now being supplanted by thousands of independent automated decisions to communicate with individual consumers at an appropriate time. Massmarketing communications in single batches personalised to meet the specific requirements of the individual consumer are now both possible and profitable. ${ }^{5}$

Given its unique ability to recognise, acknowledge, understand and serve the needs of selected consumers whose individual identities and profiles can be acquired, fragmenting markets have become a source of competitive advantage for the direct marketing industry. ${ }^{6}$

The evolution of personalised marketing programmes is, however, critically dependent on the availability of comprehensive, individual-level consumer data. All modern personalised targeting models, including artificial neural networks, and all customer profiling and data-appending 


\section{The essential role of voluntarily disclosed personal data in direct marketing applications}

practices typically incorporate such data. While individual-level transactional data can be obtained from customer records, the acquisition of insightful non-transactional data relating to interests, beliefs, values, competitor spending habits, future purchase intentions, religion, political affiliation, television viewing habits and a whole host of other lifestyle characteristics essentially relies on voluntary consumer disclosure.

The collection of non-transactional individual-level data for direct marketing purposes is based on the principle that consumers can be persuaded voluntarily to disclose personal details as a result of some type of marketing exchange process. This is usually in anticipation of some perceived benefit and includes surveys and questionnaires, direct mail and telephone orders, loyalty cards, product warranty cards, replies to direct response adverts, sweepstake promotions and rebate and redemption offers. $^{7,8}$

The experience of companies collecting individual-level consumer data within the UK suggests that many consumers are prepared to disclose such data in various forms $\mathrm{s}^{9,10}$ subject to adequate data protection safeguards and evidence of benefits arising from disclosure. ${ }^{11,12}$

\section{Effect of incomplete and falsified personal data on company profitability}

While the volume of individual-level consumer data being gathered continues to expand, there is a lack of studies that have investigated how complete and reliable such data are. This is an important gap in knowledge, because incomplete and falsified data reduce the efficiency of the direct marketing effort, and commercial decisions affecting company profitability are often made with a reliance on consumer veracity in disclosing personal data.

Companies offering credit facilities, including retailers, credit card and mail-order companies, often set initial credit limits on new applicants based on self-reported income and other variables such as date of birth, marital status, employment status, time at current address, residential status, occupation, time in occupation and other credit cards held. A company using individual-level consumer data that are to some extent unreliable may encounter increased bad debt and payment default propensities due to inaccurate initial credit limits arising from incorrectly targeted communications. ${ }^{13}$

Specialist motor insurance companies also depend on the reliability of voluntarily disclosed personal data when targeting new customers according to specific underwriting criteria. These underwriting criteria are used to establish insurance premium levels, and include an individual's postcode, vehicle make and model, occupation and date of birth. The use of falsified data leads to the targeting of misclassified market segments, thereby inhibiting the effectiveness of the direct marketing communication.

While companies can check the reliability of some elements of voluntarily disclosed data against external databases not compiled from voluntary disclosures, for example date of birth and credit card usage from the electoral roll and credit reference agencies, there remain some 
Incomplete and falsified data disclosures impede the direct marketing effort data variables that cannot be verified and corrected in this manner. For example, charitable and political affiliations, competitor spending habits and future purchase intentions cannot be verified against external sources compiled from involuntarily supplied data.

The adverse effects of falsified and omitted personal data disclosures on company profitability are not restricted to the targeting of new customers. Transactional data alone are insufficient in understanding purchase behaviours because they provide little insight into the needs that motivate the purchase process, and lack such detail as competitor spend and future purchase intentions. ${ }^{14}$ Radford's study, for example, described how the Co-operative Bank successfully abandoned its sole use of transactional data in favour of supplementing lifestyle characteristics to gain greater customer insight that contributed to increased profitability. ${ }^{15}$ Similarly, many companies are now appending externally acquired individual-level data to their transactional databases in an attempt to learn more about their customers. Again, omissions and inaccuracies in the acquired data potentially lead to misclassification of customers in the database and personalisation error. As a consequence, companies cannot be as precise in their customisation, which diminishes the efficiency of the direct marketing effort.

\section{Methodology}

The objectives of this study were to quantify typical levels of personal data omission and falsification, identify the types of personal data that tend to be omitted and falsified and gain an understanding of the underlying reasons for this occurrence.

Consideration was given to the possibility of contacting individuals who had already completed some type of direct marketing questionnaire or survey, then interviewing these individuals on the veracity and completeness of the information that they had provided. This approach was dismissed because the 1998 Data Protection Act requires that companies register the purposes for which they are gathering personal information and only use such information in accordance with those purposes. Recontacting individuals who had voluntarily disclosed personal information on a face-to-face basis was contrary to the declared direct marketing purposes of contact by post, telephone, e-mail or text messaging in the questionnaires and surveys. In addition, this approach did not allow for the relative proportions of personal data contributors and abstainers to be measured.

Personal interviews were chosen as the most appropriate data collection method because they facilitated more complete and informed responses. Additionally, it was possible to observe facial expressions and body language that communicated emotions, motivations and attitudes not apparent from non-direct methods of data collection, thereby adding greater depth in qualitative understanding. The personal interviews were conducted in a busy West Yorkshire city centre. The chosen city centre offered access to a large population whose characteristics broadly reflected those of the UK general population with respect to marital status, economic activity and age, as indicated in Table 1. 
Table 1: Comparison with national population

\begin{tabular}{|lcc|}
\hline & $\begin{array}{c}\text { Yorkshire city } \\
\text { centre } \%\end{array}$ & $\begin{array}{c}\text { UK } \\
\%\end{array}$ \\
\hline Marital status & & \\
Single (never married) & 29 & 30 \\
Married or remarried & 52 & 51 \\
Separated & 3 & 2 \\
Divorced & 8 & 8 \\
Widowed & 9 & 8 \\
Employment status & 57 & 61 \\
Employed & 4 & 3 \\
Unemployed & 13 & 14 \\
Retired & 8 & 7 \\
Looking after home/family & 6 & 6 \\
Permanently sick/disabled & 13 & 10 \\
Other & & \\
Age range & 23 & 20 \\
Under 16 & 6 & 5 \\
16-19 & 13 & 13 \\
20-29 & 39 & 42 \\
30-59 & 12 & 8 \\
60-74 & 7 & 39 years \\
75 and over & 36 years \\
\hline
\end{tabular}

Source: Office for National Statistics (2001)

\section{Personal interviews and random sampling}

Throughout, reassurance of confidentiality of the results was stressed and the interviews proceeded in a conversational manner. Responses were collected in writing during the interviews and further notes added on completion of each interview relating to facial expressions, emotions and feelings. Consistency in the manner of question presentation and surroundings was maintained to reduce the context dependency of responses; for example, the immediate environment, interviewee mood, comfort and recent experience.

All individuals who disclosed personal data for direct marketing purposes formed the basis of the target population. In recognition that personal interviews typically have a higher degree of geographic respondent locality and the potential for introducing non-coverage issues such as response bias, ${ }^{16}$ the target population was defined using a proportionately stratified, nationally representative sampling frame.

The target population was stratified based on three age bands and gender, comprising a total of six strata. Approximately one-third of the target population was assigned to each age band to ensure that the six strata were similar in size. This allowed interviewees to be assigned to each stratum without the requirement for weighting.

Individuals were approached as potential interviewees on a random basis irrespective of gender, age, outward appearance and whether alone or in a group. A total of 256 interviews were commenced to ensure that an adequate, proportionately stratified sample frame was obtained. Out of this total, 157 interviewees reported that they voluntarily disclosed some form of personal data for direct marketing purposes. In those instances where an interview commenced and the interviewee stated that he or she did not disclose personal data for direct marketing purposes then no 
further questioning regarding omission and falsification was undertaken. Only the 157 contributors of personal data were included in the study.

Where a group of two or more individuals was approached, the first individual electing to participate was asked to answer questions in isolation and far enough in distance that responses could not be overheard, preventing third-party influence. This was an important procedure, because respondents may have otherwise been tempted to answer in a manner that gave them credibility in the presence of onlookers, rather than providing truthful responses.

Table 2 shows the national proportion of individuals within each gender and age-defined stratum and Table 3 shows the actual proportion of interviewees obtained per stratum. The proportion of interviewees per stratum broadly corresponded to that of the national population.

Nationally representative results typically involve sample sizes in excess of 1,000 respondents. ${ }^{17}$ The results obtained from this study thus involved a sample size that could not be generalised across the national population. Accordingly, the results of this study must be regarded as indicative in nature rather than confirmative.

The personal interviews began by explaining to respondents the range of direct marketing data-gathering practices, to include consumer surveys and questionnaires, warranty cards, telephone and internet orders, moneyoff coupons, sweepstakes, prize draws and mail-in redemption offers. Interviewees were advised that companies must declare at the point of capture the purposes for which their personal data would be used and offer individuals the opportunity to opt out of having their data used for direct marketing purposes, commonly made available in the form of an opt-out box. In this manner, interviewees were made more aware of those practices that constituted a disclosure of personal data for direct marketing purposes.

It was noted, however, that some interviewees might not have been aware that they had actually disclosed personal data for direct marketing purposes due to the more surreptitious nature of some data-gathering

Table 2: National proportion of individuals per stratum

\begin{tabular}{|lcc|}
\hline Age group & $\begin{array}{c}\text { Male } \\
\%\end{array}$ & $\begin{array}{c}\text { Female } \\
\%\end{array}$ \\
\hline $18-34$ & 14 & 16 \\
$35-54$ & 18 & 18 \\
55 and over & 16 & 18 \\
\hline
\end{tabular}

Table 3: Actual proportion of interviewees per stratum

\begin{tabular}{|lcccc|}
\hline Age group & $\begin{array}{c}\text { Male } \\
\text { (no.) }\end{array}$ & $\begin{array}{c}\text { \% of } \\
\text { total }\end{array}$ & $\begin{array}{c}\text { Female } \\
\text { (no.) }\end{array}$ & $\begin{array}{c}\% \text { of } \\
\text { total }\end{array}$ \\
\hline $18-34$ & 20 & 13 & 26 & 17 \\
$35-54$ & 27 & 17 & 30 & 19 \\
55 and over & 27 & 17 & 27 & 17 \\
\hline
\end{tabular}




\section{The majority of voluntarily disclosed personal data is incomplete}

methods. Even with a prior explanation of direct marketing datagathering techniques, it was therefore recognised that the proportion of interviewees realising that they disclosed personal data might have been understated compared to 'real-life' situations.

Interviewees were asked: 'Do you disclose personal data for direct marketing purposes?' Those interviewees who indicated that they did disclose personal data for direct marketing purposes were asked to rate their typical frequency of data omission on a five-point scale through the question: 'When disclosing personal data, how many of the questions do you typically complete?' Possible anwers were 'All of them', 'More than half', 'Roughly half', 'Less than half' and 'Hardly any'. Where an interviewee stated that they omitted data, the question was posed: 'What type of questions are you least likely to answer and why?'

Next, interviewees were asked to rate their level of falsification on a five-point scale through the question: 'How often do you knowingly provide false data?' Answers were 'Never', 'Not very often', 'Sometimes', 'Often' and 'Very often'. Those interviewees who acknowledged falsification of personal data were asked: 'What type of questions are you likely to falsify and why?' Interviewees were reassured of confidentiality at this stage due to the sensitive nature of the questioning, and were encouraged to be as truthful as possible in their responses.

\section{Results and discussion Incidence of abstention}

A total of 157 interviewees (61 per cent) reported that they voluntarily disclosed some form of personal data for direct marketing purposes, while 99 interviewees ( 39 per cent) abstained. Although the results could not be generalised across the national population due to the sample size employed, this finding suggested that there existed a substantial proportion of consumers within the general population who were unwilling voluntarily to disclose personal data.

\section{Prevalence of omissions}

Table 4 shows that only a minority ( 15 per cent) of interviewees typically disclosed all data requested. While 78 per cent completed half or more of the questions posed, a small minority ( 9 per cent) reported that they completed 'hardly any' questions. Essentially, these findings indicated that the majority of personal data disclosed for direct marketing purposes were, to varying degrees, incomplete.

The hypothesis that there is a skew in consumers' propensity to omit specific details when disclosing personal data for direct marketing purposes was assessed using the goodness-of-fit chi-square test.

- Null hypothesis $\left(\mathrm{H}_{0}\right)$ : There is no skew in consumers' propensity to omit specific details when disclosing personal data for direct marketing purposes.

- Alternative hypothesis $\left(\mathrm{H}_{\mathrm{A}}\right)$ : There is a skew in consumers' 
Consumer attitudes towards disclosing personal data

Table 4: Incidence of omissions in disclosed personal data

\begin{tabular}{|lcrc|}
\hline Response & Observed number & $\%$ & Expected number \\
\hline All of them & 24 & 15 & 31.4 \\
More than half & 49 & 31 & 31.4 \\
Roughly half & 50 & 32 & 31.4 \\
Less than half & 20 & 13 & 31.4 \\
Hardly any & 14 & 9 & 31.4 \\
Total & $\mathbf{1 5 7}$ & $\mathbf{1 0 0}$ & $\mathbf{1 5 7 . 0}$ \\
\hline
\end{tabular}

propensity to omit specific details when disclosing personal data for direct marketing purposes.

Table 4 provides a chi-square value of 36.3. Two levels of significance $(\alpha)$ were assessed: 5 per cent and 1 per cent, using four degrees of freedom calculated as $\mathrm{k}-1$ where $\mathrm{k}$ is the number of categories. The following critical values were obtained:

$$
\begin{aligned}
& \chi^{2} 0.05,4=9.5 \\
& \chi^{2} 0.01,4=13.3 .
\end{aligned}
$$

At both levels of significance the null hypothesis was rejected, supporting the alternative hypothesis that there is a skew in consumers' propensity to omit specific details when disclosing personal data for direct marketing purposes, towards lower levels of such data typically being omitted.

\section{Typology and reasons underlying omissions}

Only those interviewees who reported that they omitted data were eligible to respond to the question 'What type of questions are you least likely to answer and why?' This constituted 133 out of the 157 interviews.

A universal theme to emerge was the unwillingness of interviewees to disclose what they perceived to be sensitive data, especially data relating to income and health. This was typified by comments such as 'Private data I'd only give to a doctor or bank' and 'What I consider to be private such as salary or health'. Responses were expressed intensely and affirmatively, emphasising the importance attached to such data.

Interviewees regarded sensitive data as confidential in nature and distinct from less-sensitive data on subjects such as hobbies and interests: 'Salary and health. These are private and not for them to know.' Effectively, these interviewees represented a sub-segment of abstainers; that is, rather than abstaining completely from disclosing personal data for direct marketing purposes they did so selectively. Omission of

Omission of sensitive data is a selective form of abstention sensitive data was essentially a selective form of abstention.

These findings concurred with secondary data obtained from a 2004 UK nationally distributed consumer survey. The source of the survey is not disclosed for reasons of commercial confidentiality. Though only nine variables were made available, the results shown in Table 5 reveal that the propensity of consumers to omit particular types of personal data is related to the type of data requested. More precisely, Table 5 confirms the 
Table 5: Omissions in personal data

\begin{tabular}{|lc|}
\hline Data variable & \% omission \\
\hline Gender & 0.0 \\
Marital status & 0.0 \\
Age & 0.0 \\
Lifestyle interests & 2.6 \\
House type & 3.4 \\
Occupation & 6.7 \\
Number of children & 9.1 \\
Household income & 11.5 \\
Credit card usage & 16.0 \\
\hline
\end{tabular}

amenability of consumers towards the disclosure of less-sensitive data such as gender, marital status, age and lifestyle interests. In contrast, financial data such as income and credit card usage were more likely to be omitted.

Having described the types of personal data they were most likely to omit, interviewees were then asked to explain their reasons for omission. The most prevalent reason underlying omission was data protection concerns. Specifically, it was feared that sensitive data might be disseminated to third parties, leading to privacy intrusion: 'I'm worried that personal data such as health and finances will be passed on' and 'Very private stuff I don't want passing on.'

Interviewees also omitted data relating to what they regarded as overly long or complicated questions, and where they lacked requisite knowledge to offer an informed response. Effectively, data omission offered a route to hastening and simplifying the response process: 'Long, drawn-out questions that take ages to complete', 'Long-winded, difficult and irrelevant questions I miss out' and 'Difficult ones I don't understand.'

\section{Prevalence of falsification}

Table 6 shows that only a minority ( 46 per cent) of interviewees 'never' knowingly disclosed false personal data. But a total of 76 per cent of interviewees either 'never' or 'not very often' falsified personal data, indicating that the general incidence of corrupted data was relatively low.

The hypothesis that there is a skew in consumers' propensity to falsify specific details when disclosing personal data for direct marketing purposes was assessed using the goodness-of-fit chi-square test.

Table 6: Incidence of personal data falsification

\begin{tabular}{|lcrc|}
\hline Response & Observed number & $\%$ & Expected number \\
\hline Very often & 8 & 5 & 31.4 \\
Often & 12 & 7 & 31.4 \\
Sometimes & 17 & 11 & 31.4 \\
Not very often & 47 & 30 & 31.4 \\
Never & 73 & 46 & 31.4 \\
Total & $\mathbf{1 5 7}$ & $\mathbf{1 0 0}$ & $\mathbf{1 5 7 . 0}$ \\
\hline
\end{tabular}


- Null hypothesis $\left(\mathrm{H}_{0}\right)$ : There is no skew in consumers' propensity to falsify specific details when disclosing personal data for direct marketing purposes.

- Alternative hypothesis $\left(\mathrm{H}_{\mathrm{A}}\right)$ : There is a skew in consumers' propensity to falsify specific details when disclosing personal data for direct marketing purposes.

Table 6 provides a chi-square value of 104.3. Two levels of significance $(\alpha)$ were assessed: 5 per cent and 1 per cent, using four degrees of freedom calculated as k-1 where $\mathrm{k}$ is the number of categories. The following critical values were obtained:

$$
\begin{aligned}
& \chi^{2} 0.05,4=9.5 \\
& \chi^{2} 0.01,4=13.3
\end{aligned}
$$

At both levels of significance the null hypothesis was rejected, supporting the alternative hypothesis that there is a skew in consumers' propensity to falsify specific details when disclosing personal data for direct marketing purposes, towards lower levels of such data being falsified.

Incidences of personal data falsification were lower than incidences of

Levels of personal data falsification are typically low omission. Such data are more likely to be omitted than falsified in response to a perceived threat.

\section{Typology and reasons underlying falsification}

The interviewee sample size were reduced to 84 after excluding those who stated that they never knowingly provided false data.

The most frequently falsified data were what interviewees perceived to be sensitive, particularly income and health-related questions: 'Private questions such as my health or how much money I get' and 'Life insurance and questions about your health.' These were basically the same types of data that interviewees were most likely to omit. But in contrast to omission of personal data, interviewees also reported other types of sensitive data that they were prepared to falsify. These included falsification of questions relating to the environment, diet, alcohol consumption, smoking and charitable donations: 'Charities, health, diet and other stuff' and 'Eating, smoking and drinking.'

Interviewees were then asked to describe their reasons for falsification. The major reason cited for falsification of personal data was data protection concerns; specifically concerns that data would be passed to third parties, leading to the receipt of unwanted marketing communications, commonly referred to as 'junk mail'. For example, by falsely indicating no interest in a given subject it was believed that marketing communications would be avoided. Again, this was the main reason cited for omission of data. Typical comments included: 'I change data I provide for things such as life insurance, saying I'm not interested because they ring you all the time trying to sell stuff' and 'I put "no" against some questions so they won't start sending me junk mail if they think I might be interested, things like a new car or home improvements.' 
Omission of personal data is correlated with falsification
A further reason for falsification was the desire to appear socially responsible. This situation was more pronounced with respect to questions relating to environmental, health and charitable concerns. Interviewees were reluctant to express a lack of ecological concern, to acknowledge poor eating habits or disinterest in charitable affairs: 'I might sometimes exaggerate stuff to look better, like diet and exercise' and 'To appear responsible on things like diet and smoking.' Social conditioning led interviewees to provide what they perceived to be 'correct' answers in the belief that they were acting responsibly.

Finally, interviewees falsified data relating to overly long questions on direct marketing data-gathering devices, and because of difficulty in interpreting the questions and subsequent failure to respond correctly. Falsification thus provided a route to reducing the time and effort involved in the disclosure process: 'To speed up filling in the form, such as saying I'm not interested in a certain thing and jumping to the next section' and 'I might guess the answer wrongly if I don't understand the question.'

\section{Relationship between omission and falsification of personal data} Given the apparent similarity in the reasons underlying omission and falsification of personal data, Pearson's correlation coefficient was used to ascertain if a relationship existed between interviewee propensity to omit and to falsify personal data. Pearson's correlation coefficient has a range from +1 indicating a perfectly positive relationship to -1 indicating a perfectly negative relationship. A result of +0.49 was obtained.

This positive correlation was tested for statistical significance at the 5 per cent level (1.96) and the 1 per cent level (2.58) using the formula:

$$
\frac{\mathrm{r} \sqrt{ }(\mathrm{n}-2)}{\sqrt{ }\left(1-\mathrm{r}^{2}\right)}
$$

where $\mathrm{r}$ is Pearson's correlation coefficient and $\mathrm{n}$ is the sample size.

A result of +7.00 was obtained, confirming a strong correlation between propensity to omit and propensity to falsify personal data. Essentially, where there is a high incidence of omitted data there is likely to be a correspondingly greater level of falsification.

\section{Conclusion}

The following limitations in the research should be noted.

Firstly, since the personal interviews were conducted at a single point in time the findings do not reflect future isolated events or changes in social forces that may affect consumer perceptions of direct marketing activities. In particular, levels of public awareness of the collection and use of personal data are likely to increase over time as more businesses embrace direct marketing methods, which will in turn increase the prevalence of data protection concerns. This is an important point, because this study has shown that data protection concerns can influence the propensity of consumers to omit and falsify such data. The completeness and reliability of individual-level consumer data may thus be related to changes in the external environment. As a consequence, the 
results have a limited period of applicability and should be retested before being applied to areas of further study.

Secondly, the quantitative findings cannot be generalised across the national population due to the sample sizes used. Accordingly, the study's findings are indicative in nature, rather than laying claim to being conclusive or confirmative.

Consumers have a hierarchy of data that they are prepared to disclose, ranging from relatively harmless details such as name and address to details of income and personal finance. There is a reluctance to disclose what are perceived as sensitive data, but greater amenability to the disclosure of more innocuous details. Those companies seeking to acquire more sensitive personal data, particularly those relating to finance and health, are likely to encounter higher rates of omission and falsification in voluntary disclosures. This leads directly to the postulation that the financial services and health-related market sectors will be worst affected by these phenomena.

Previous studies have tended to focus on the effects of data protection concerns on willingness to disclose personal data. This represents too narrow an interpretation of the effects of data protection concerns, since such concerns are manifested not solely in terms of a dichotomous choice between voluntary disclosure of personal data and abstention, but may also affect both the completeness and the reliability of such data. In addition, omission of certain types of data can be regarded as a selective form of abstention. That is, consumers respond to perceived data protection threats in one of two ways: either by refusing to engage in direct marketing data-capture requests altogether, or by doing so selectively through the withholding of sensitive data.

The primary reason for omission and falsification of personal data is concern that sensitive details might be disseminated to third parties, leading to privacy intrusion in the form of unwanted communications such as mailings and telemarketing, frequently described as 'junk mail' and 'sales calls'. Consumers also omit and falsify data relating to what they perceive to be overly long or complicated questions in an effort to simplify the response process. Misunderstanding and the desire to present socially desirable responses further contribute towards falsification. Companies may thus be able to acquire more complete and reliable individual-level consumer data by emphasising data protection guarantees, by ensuring that data-capture mechanics are concise and relevant and by shortening and simplifying questions to reduce respondent fatigue and interpretation difficulties.

The findings of this study indicate a significant skew toward typically low levels of omission and falsification in volunteered personal data. Within this, consumers appear much more likely to omit than to falsify such data.

Finally, the incidence of personal data omission appears to be directly related to the incidence of falsification. Levels of omitted personal data can therefore serve as a useful indicator of levels of falsification. This is an important point because, while it is relatively easy to determine levels of omitted data, no obvious mechanism exists for establishing reliability. 
Where companies encounter higher levels of omission it is more likely that the data will also be falsified.

\section{Further research}

A number of testable predictions and areas for further research emerge from this study.

Generalisation of the results across the national population could be achieved by repeating the study using a sample size in excess of 1,000 personal interviewees.

This study postulates that data protection concerns affect the completeness and reliability of disclosed personal data, a finding that could be tested by comparing those consumers with high data protection concerns against those with low concerns. Those with high data protection concerns are expected to disclose a greater proportion of incomplete and falsified data than those with lower data protection concerns. Further empirical research in this area could be undertaken to verify the study's findings.

The findings of this study lead to the postulation that consumers omit personal data as a selective form of abstention. If correct, then abstention rates should co-vary with omission rates.

\section{References}

1. Robertshaw, G. S. (2000) 'The segmentation and targeting of consumers within the fragmenting UK mail order market', Journal of Segmentation in Marketing, Vol. 4, No. 1, pp. 27-51.

2. Wind, J. and Rangaswamy, A. (2001) 'Customerisation: The next revolution in mass customisation', Journal of Interactive Marketing, Vol. 15, No. 1, pp. 13-32.

3. Radford, M. (2004) 'Personal financial services in a digital age', Journal of Consumer Behaviour, Vol. 2, No. 3, pp. 287-296.

4. Courtheoux, R. J. (2000) 'Database marketing connects to the internet', Interactive Marketing, Vol. 2, No. 2, pp. 129-137.

5. Zineldin, M. (2000) 'Beyond relationship marketing: Technologicalship marketing', Marketing Intelligence and Planning, Vol. 18, No. 1, pp. 9-23.

6. McCorkell, G. (1998) 'How marketing went direct', The Direct Marketing Guide, Vol. 1, Institute of Direct Marketing, Teddington.

7. Lix, T. (1995) 'New customer acquisition: Prospecting models and the use of commercially available external data', Journal of Direct Marketing, Vol. 9, No. 4, pp. 9-20.

8. Reed, D. (1999) 'Consumer lifestyle data', Precision Marketing, 8 February, pp. 7-9.

9. Croft, M. (1997) 'Facts of life (lifestyle databases)', Marketing Week, 1 May, pp. 43-45.

10. Gofton, K. (1999) 'Data firms react to survey fatigue', Marketing, 29 April, pp. 16-18.

11. Henley Centre (1995) quoted in The Direct Marketing Guide, Vol. 1, Institute of Direct Marketing, Teddington, p. 9.

12. Kleinman, M. (1999) 'News analysis', Precision Marketing, 16 November, pp. 11-12.

13. Robertshaw, G. S. (2005) 'What are the limitations in the gathering of individual-level consumer information for direct marketing purposes?', $\mathrm{PhD}$ thesis, Huddersfield University Business School, Huddersfield.

14. Peltier, J. and Schribrowsky, J. A. (1997) 'The use of need-based segmentation for developing segment-specific direct marketing strategies', Journal of Direct Marketing, Vol. 11, No. 4, pp. $53-63$. 
Consumer attitudes towards disclosing personal data

15. Radford, ref. 3 above.

16. Lehman, D. R., Gupta, S. and Steckel, J. H. (1998) Marketing Research, Addison-Wesley, New York.

17. Ibid. 